\title{
CULTURE AND SOCIAL MEDIA USAGE: ANALYSIS OF JAPANESE TWITTER USERS
}

\author{
Adam Acar \\ Kobe City University of Foreign Studies \\ 9-1, Gakuen-higashi-machi, Nishi-ku, Kobe 651-2187, Japan \\ acar@inst.kobe-cufs.ac.jp \\ Ayaka Deguchi \\ Kobe City University fo Foreign Studies \\ 9-1, Gakuen-higashi-machi, Nishi-ku, Kobe 651-2187, Japan
}

\begin{abstract}
Twitter, one of the most popular microblogging tools, has been used extensively all around the world. However, up to date, no study has addressed how culture influences the use of this communication platform. In order to close the literature gap and promote cross-cultural understandings, this paper content analyzed 4,000 tweets from 200 college students in Japan and the USA. The results showed that Japanese college students post more self-related messages and ask fewer questions compared to American college students. It was also found that tweets that refer to TV are more common in Japan, whereas sports and news tweets stand out in the USA. The evidence from this study suggests that there is a subtle and complicated relationship between culture and Twitter use.
\end{abstract}

Keywords: Twitter, Japan, Social Media, Culture

\section{INTRODUCTION}

Microblogging is a new communication style that allows users to post their current status, usually within 200 characters, which is then distributed by instant messages, mobile phones, email, or the $\mathrm{Web}^{1}$. Microblogs allow users to share and exchange real-world information ${ }^{2}$ publicly or semi-publicly ${ }^{3}$, which perhaps explains the popularity of these platforms. As of April 2011, Twitter, the largest microblogging site, had about 300 million users worldwide ${ }^{4}$ and has been regarded as one of the top 3 social networks alongside Facebook and LinkedIn ${ }^{5}$. 
Up to date, a number of studies analyzed the use of Twitter from different perspectives. Lento et al. $^{6}$ examined the relationship between social ties and Twitter usage. Vieweg et al. ${ }^{7}$ investigated the use of Twitter during natural disasters. However, few studies focused on the relationship between the use of microblogging services and cultural values. This paper aims to close this literature gap by cross-culturally analyzing the tweets of randomly selected Japanese and American college students.

\section{WHAT IS TWITTER?}

Microblogging "is a new form of communication in which users can describe their current status in short posts distributed by instant messages, mobile phones, email or the Web (pp. 1)" ${ }^{\prime 1}$. Passant et al. ${ }^{8}$ insist that as a simple and speedy communication form, microblogging makes it easier to update and exchange information. According to Sakaki, Okazaki, and Matsuo $^{9}$, all microblogging services have one thing in common: real-time information update (p.1). They also insisted that unlike typical bloggers who post to their blogs a few times a month, microbloggers post tweets several times a day or more (p.2). According to Java and his colleagues, Twitter has been one of the most popular microblogging sites. It has experienced a huge growth since its launch in October 2006. Huffington Post ${ }^{5}$ reports that the number of tweets posted on the site on an average day grew from 50 million to 140 between 2010 and 2011, in addition to a substantial increase in the number of new users. Today, Twitter has more than 300 million users worldwide ${ }^{4}$.

Although Twitter was founded as a microblog where users only updated their status, over the past few years, people started to share other things such as what they were doing, their intentions, and so on ${ }^{10}$. "Twitter is more and more becoming a key player in the attention economy, distributing comments about what its users are paying attention to, what they have opinions about, and what they have expertise in (pp. 3)." Therefore, it is crucial for us to understand the dynamics of Twitter in order to be able to predict how people adopt and utilize new communication tools.

\section{WHY DO PEOPLE MICROBLOG?}

According to Java et al. ${ }^{1}$, there are three types of microblogging: information sharing, information seeking, and friendship-wise relationship. Günther et al. ${ }^{11}$ identified three factors that influence the adoption of Twitter, including signal-to-noise ratio, privacy concerns, and perceived communication benefits. Günther et al. $^{11}$ emphasized the aspect of information speed, writing, "Not only has Twitter proven to be a convenient 
means to exchange trivia, it has also received public attention due to its ability to rapidly spread news. For example, before reaching any major news station, Twitter users have broadcasted about the Hudson River plane crash landing - one of them even being on the ferry boat heading out to rescue the passengers" (p.1). Communication rapidity was also mentioned by Vieweg et al. ", who regarded Twitter as one of the "best emergency communication tools."

Ebner and Schiefner ${ }^{12}$ suggested that the biggest difference between blogs and microblogs is speed. According to the authors, ordinary blogs were perceived as tools that can be used for coherent statements, knowledge saving, and discourse. Microblogs, on the other hand, are used mostly to write about users' thoughts and quick reflections. Ebner and Schiefner ${ }^{12}$ also insisted that communication is the most essential part, and microblogging allows us to communicate in different ways.

\section{TWITTER IN JAPAN}

The Japanese version of Twitter was launched in April 2008. According to the research conducted by Fujitsu in $2010^{13}$, the most active users of Twitter in Japan (14. 9\%) are among the younger generation (age 15-19). This research also shows that younger users view Twitter as a real-time communication tool. On the other hand, the older generation tends to use Twitter mostly to gather information. Compared to adolescents, they tweet less frequently ${ }^{13}$. Nakamura and Deguchi ${ }^{14}$ described the main feature of Twitter as:

Contrasting with the other social networking services such as Mixi, Twitter is quite unique because of its directedness when viewed as a network. In Twitter's network, like the other social networks, vertices represent users and edges represent friendships between users. Edges have directions, "following" or "followed", and thus friendships can be either one-way or two-way. (p.2)

According to $\mathrm{Kin}^{15}$, Twitter is similar to Mixi, Japan's largest social network, because both services allow users to post their daily thoughts. However, the services differ in terms of the network structure. Kin further maintained that Mixi's being a closed network makes Twitter more attractive for not only mainstream Japanese users but also Japanese companies, since it is easier to track what people are talking about on Twitter (p.80). 


\section{CULTURAL DIFFERENCES BETWEEN JAPAN AND THE WEST}

\subsection{Values}

Individualism and collectivism are the major dimensions of cultural variability that are used to explain cross-cultural differences ${ }^{16}$. According to Hofstede ${ }^{17}$, individualistic societies emphasize "I", the individual, whereas collectivistic societies focus on "we", the group. Individualistic societies put more value on achieving individual potential and personal freedom. Hofstede $^{17}$ indicates that people in collectivistic societies are and heavily influenced by the groups they are part of. On the contrary, in individualistic societies, there is more independence and people are less likely to conform to social norms.

Although we can naturally presume that Americans in general are more individualistic than Japanese, Oyserman et al. ${ }^{18}$ tested the magnitude of this difference in a cross-cultural study. His findings indicated that, overall, Americans reported to be more individualistic (IND) than did Japanese when individualism evaluations included personal uniqueness, valuing privacy, and direct communication. However, when personal uniqueness was excluded, Americans scored lower in IND than did Japanese. Further, Japanese seemed to value personal privacy more than Americans. Oyserman et al. ${ }^{18}$ pointed out that Japanese score higher on collectivism when it comes to preserving group harmony and working collectively, but it is difficult to label them as a collectivistic nation.

\subsection{Context-Based Communication}

Hall $^{19}$ suggested that cultures can be categorized into two categories based on the influence of contextual factors on communication processes. According to Hall, high-context messages are implicit and not openly coded and transmitted, while low-context messages are direct and explicit. As Hall ${ }^{19}$ explains:

Japanese, Arabs, and Mediterranean people, who have extensive information networks among family, friends, colleagues, and clients and who are involved in close personal relationships, are high-context. As a result, for most normal transactions in daily life they do not require, nor do they expect, much in-depth, background information. Low-context people include Americans, Germans, Swiss, Scandinavians, and other northern Europeans; they compartmentalize their personal relationships, their work, and many aspects of day-to-day life. Consequently, each time they 
interact with others they need detailed background information. (p.6)

Gudykunst ${ }^{16}$, who examined contextual cues in Japan and the USA, concluded that both countries are dramatically different from each other. The authors claimed that Japan is a high-context culture where messages are ambiguous and focused on maintaining harmony. Conversely, American culture tends to be low context that is direct, open, and based on true intentions and feelings ${ }^{16}$.

The indirect nature of context-based communication and the unique style of Japanese self-expression are likely to influence microblogging behavior in Japan. Japan is high-context culture and Japanese people are not so comfortable with sharing background information with others easily ${ }^{20}$. In addition, Japanese culture stresses the importance of group solidarity, whereas American culture tends to focus on independence and self-promotion ${ }^{17}$. Therefore, I propose that Japanese in general tweet about others and Americans post tweets that are related with self-promotion. Thus, my hypotheses are:

H1: Japanese users post fewer self-related tweets than do Americans.

H2: American users post more self-promotion related messages than do Japanese.

Lastly, our literature review indicated that people in low-context cultures learn to compartmentalize information about their lives ${ }^{16}$ which necessitates more questions in daily conversations. Miller ${ }^{21}$ explains why Japanese shy away from asking questions:

Asians are required to know others' feelings even if the others remain silent. We are supposed to guess if the other person is thirsty and offer tea. So, I think that the Japanese are bad at asking for help. We cannot ask for help from a person whom we've just met. But if we remain silent, the Americans tend to think that we are all right. (p. 11)

As members of a low-context culture, Americans are expected to ask more questions to clarify meanings and seek new information. Thus, we propose:

H3: American users ask more questions on Twitter than do Japanese. 


\section{METHODOLOGY}

A content analysis was performed to assess how the Japanese and American young generations use Twitter. One hundred college students from both Japan and the USA were randomly selected and the last 20 tweets $(\mathrm{N}=4000)$ they posted were categorized into 7 previously identified categories. The details about the participants, instrument, and procedure are described below.

\subsection{Participants}

To obtain a random sample of users in both countries, we searched user profiles by using Twitter's own search engine. After entering the keywords “大学生です” (I am a college student) and "student \& university", we selected the first 100 Japanese university students and 100 American university students who showed up in the search results. We particularly have chosen only individual Twitter users by excluding spammers, bots, marketers, organizations, and companies. Additionally, in order to eliminate dead and inactive accounts, only users who had at least 10 friends, 10 followers, had tweeted in 7 days, and had posted at least 500 messages were included in the study ${ }^{3}$. The male/female ratio was 50:50, and whether the user is male or female was determined by user name, profile information, and profile pictures.

\subsection{Coding}

The unit of analysis in this study was a single tweet. To analyze the content of tweets, the last 20 tweets of each user were retrieved and coded, except for direct replies (tweets that address another specific user with "@username"). Overall, a total 4000 tweets were obtained, which were then coded into 7 categories, 2 sub-categories, and 5 genres derived from Naaman et al. ${ }^{3}$. A single bilingual Japanese coder coded the tweets during the 4th week of November and the 1st week of December 2011. For the tweets that had more than 1 category, as a rule, the main focus of the tweet was coded as a single category.

\section{FINDINGS}

The comparison of tweets from Japan and the USA has shown that the content of tweets was dramatically different on the two sides of the Atlantic. As can be seen in Figure 1, the category of self-related random thought was the most common tweet type both in Japan and the USA. However, Japanese college students tweeted more self-related thoughts than did American college students $($ Japanese $=39 \%$, Americans $=31 \%)$. Moreover, 
there were more friends- and family-related tweets in the American sample (13\%) when compared with the Japanese sample (6\%). Since Chi-square tests also indicated that these differences are statistically significant, we

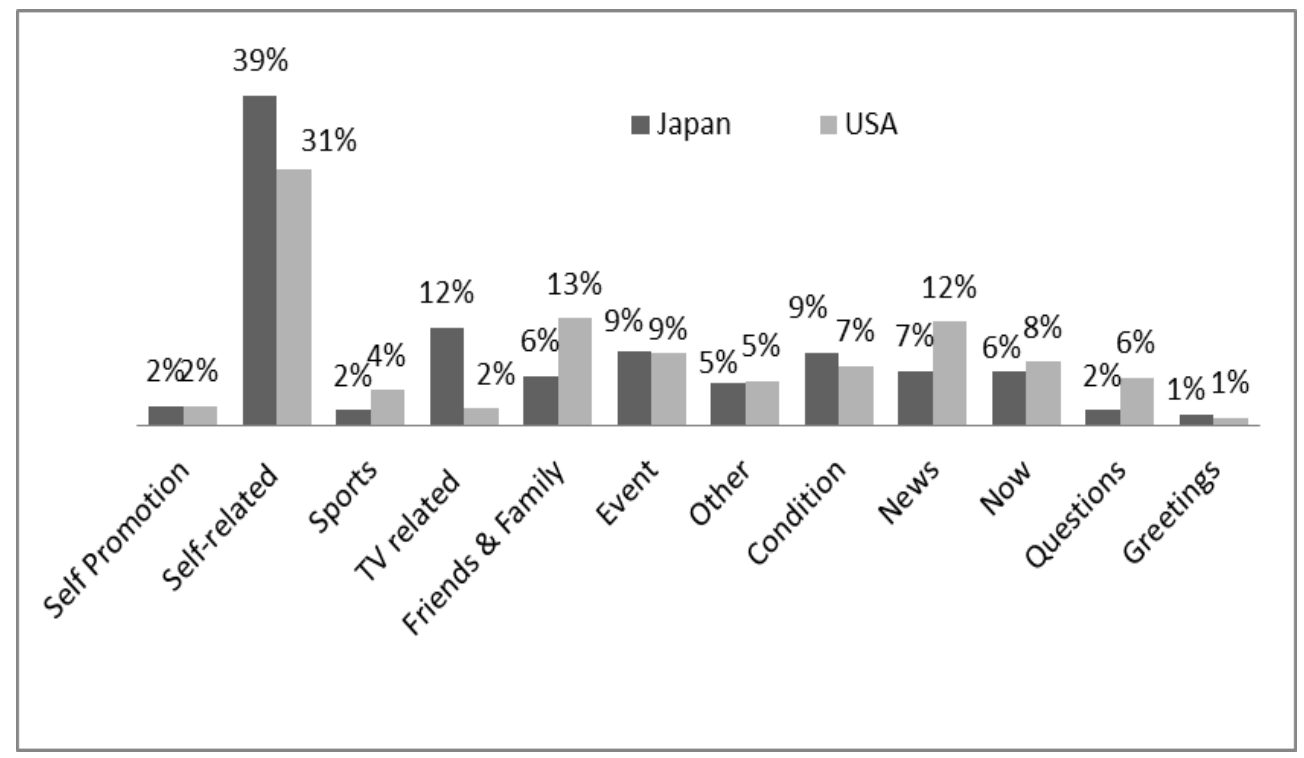

rejected both $\mathrm{H} 1$ and $\mathrm{H} 2$.

Figure 1. Comparison of Japanese and American tweets $(n=2000)$

Table 1. Chi-square test results

\begin{tabular}{lccc}
\hline \multicolumn{1}{c}{ Category } & $\begin{array}{c}\text { Pearson } \\
\text { Chi-square Value }\end{array}$ & $d f$ & P Value \\
\hline Self-Promotion (Japan * USA) & 0.011 & 1 & 0.916 \\
Self-related (Japan * USA) & 33.227 & 1 & 0 \\
Sports (Japan * USA) & 19.794 & 1 & 0 \\
TV (Japan * USA) & 148.481 & 1 & 0 \\
Friends \& Family (Japan * USA) & 56.172 & 1 & 0 \\
Event (Japan * USA) & 0.05 & 1 & 0.823 \\
Other (Japan * USA) & 0.127 & 1 & 0.721 \\
Condition (Japan * USA) & 3.518 & 1 & 0.061 \\
News (Japan * USA) & 40.489 & 1 & 0 \\
Questions (Japan * USA) & 40.805 & 1 & 0 \\
Greeting (Japan vs. USA) & 1.012 & 1 & 0.314 \\
Now (Japan vs. USA) & 2.392 & 1 & 0.122 \\
\hline
\end{tabular}

Additionally, we observed that sports, TV, news, and question categories were significantly different in both samples. The biggest 
difference was the TV-related messages, which were common in Japan (12\%) and almost nonexistent in the US (2\%). To test H3, we further carried out a Chi-square test and found that the difference in the questions category was statistically significant (Chi-Square value $=40.85, \mathrm{p}<.05$ ). Thus, we accepted H3.

All tweets were also separately analyzed by gender and country, which provided some insightful gender differences. As gender communication is not the scope of this paper, the differences will not be discussed.

\section{DISCUSSIONS}

This study was carried out to determine whether cultural differences are reflected in microblogging behavior. The first hypothesis was "Japanese users post fewer self-related tweets than do Americans," and we found the opposite. Interestingly, we observed that many Japanese users tweet about themselves $($ male $=34 \%$, female $=45 \%)$. Thus, we rejected H1. This finding can be explained with Twitter's main purpose, which is self-expression .On its website, Twitter asks its users to tweet about what they are up to (いま何 してる? ). Instead of using Twitter as an interpersonal communication tool, apparently Japanese users just post what they are doing or thinking about.

The second most commonly observed category in the Japanese sample was TV-related random thoughts. Originally, we did not have any subcategory for random thoughts since the coding form was based on the past similar studies mentioned above. After the initial phase of coding we noticed that there were big differences in the areas of TV, sports and News, so that we created 6 subcategories for random thoughts to address these important differences. We found that TV-related random thoughts were not only most common in Japan but also a category that represented a huge variation. We think this is mostly because a) contrary to the US, there's only one central time-zone in Japan where all TV shows are broadcasted about the same time $b$ ) the average Japanese family watches 8 hours of TV a day ${ }^{22}$ which means TV directly or indirectly influences daily life and interactions. Readers should note that TV-related category represented all the tweets that mentioned anything that involves TV programs, TV shows, dramas, TV series, soap operas, television, TV, movies on TV and so on.

Our second hypothesis was "American users post more self-promotion related messages than do Japanese." In terms of self-promotion, there were no significant differences between the countries. Thus, we rejected H2. This finding can be explained by the detailed reason why people use Twitter. After comparing Twitter with other communication tools, Fitton et al. ${ }^{23}$ 
stated:

Instant messaging lacks the social network "following" features of Twitter and basic ideas like "publish- subscribe" and one-to-many broadcasting of messages. Twitter has noticed that it acts like a "pulse of planet", a zeitgeist of what everyone is thinking about and feeling right now. (p.8)

Although Twitter is known to be an interactive communication tool, its service offers users an indefinite number of opportunities. The loose structure of networks on Twitter makes people less interested in using it as an interpersonal communication tool compared to other platforms. Therefore, although Americans are higher in individualism and emphasize "I" in their culture, they do not have to focus on themselves on Twitter. In the same line, our findings also suggest that the individualistic culture of the USA is not reflected on the tweets of American users.

We accepted our third hypothesis: "American users ask more questions on Twitter than do Japanese." According to Gudykunst and Nishida ${ }^{20}$, Japan is a collectivistic society where interdependent thinking is taught and encouraged. "This leads to an emphasis on wa (keeping harmony) in group, as well as emphasis on enryo (feeling of constraint and or reserve) in interactions with others" (p.112). Because of this particular aspect of Japanese culture, Japanese users perhaps stay away from posting any message that includes a question. Asking a question, which is similar to requesting something, is not a sign of constraint and reservation.

According to Adler and Proctor ${ }^{24}$, "members of high-context cultures are more curious in their first encounters of strangers and make more assumptions about them based on their backgrounds than do members of low-context cultures" (p.277). In addition, Davies and Ikeno ${ }^{25}$ explain that people in high-context culture shy away from asking many questions. On the contrary, in low context cultures, asking questions is encouraged since it eliminates ambiguity and uncertainty. The higher frequency in the American sample can be attributed to the need for directness and clarity. American users perhaps asked questions in order to clarify the meaning of other users' tweets; on the other hand, there were few questions in the Japanese sample because asking questions might be seen as disturbing others in high-context cultures.

\section{CONCLUSION}

It was found that both Japanese and American college students use Twitter to mostly post self-related random thoughts regardless of cultural 
differences. However, contrary to what we hypothesized, we observed that Japanese users post more self-related messages than do American users, which can be attributed to the loose network structure and anonymity on Twitter. It is likely that Twitter is not considered as a direct interpersonal communication tool like the telephone or e-mail, but just a platform where one can update his/her status without worrying about social norms.

Perhaps the most interesting finding in this study was the difference in the frequency of questions in Japanese and American tweets. Questions in the American sample were more common than the Japanese sample, indicating that Japanese users tend not to ask questions on Twitter as much as Americans do. We interpreted this finding as a consequence of harmony encompassed in Japanese culture. Obviously, Japanese users didn't want to ask many questions online because asking questions to others is a sign of disrespect and disharmony. On the other hand, Americans asked many questions because in low-context cultures, asking questions is seen as a sign of interest, assertiveness, and a means to make communication go more smoothly.

Lastly, the fact that American users had more friends-and-family-related messages and fewer self-related messages can also be tied to Japan's harmony-focused culture. Japanese users might have thought that mentioning someone else in a tweet might be perceived intrusive or make others feel obligated to respond. Thus, the high rate of self-related and low rate of others-related messages in Japanese tweets should not be considered as selfishness, but as an outcome of social sensitivity in Japanese culture.

\section{LIMITATIONS}

There are several limitations with the present research. First, there were small numbers of participants and restricted coding categories. Second, because of the anonymity on Twitter, it was quite difficult to make sure that users are who they say they are. It is possible that some of the tweets analyzed in this study were actually not posted by real college students. Thirdly, for the tweets that might have multiple categories, we choose only one category which is a subjective procedure that might have slightly biased the data. Lastly, there was only one bilingual coder and no other coder to check for inter-coder reliability. Future multi-country and multi-coder studies involving larger numbers of users are needed to address these problems. 


\section{REFERENCES}

[1] A. Java, X. Song, T. Finin, and B. Tseng, Why we Twitter: Understanding microblogging usage and communities. In H. Zhang, B. Mobasher, C.L. Giles, A. McCallum, O. Nasraoui, M. Spiliopoulou, J. Srivastava, and J.Yen (Eds.), Proceedings of the NinthWebKDD and First SNA-KDD 2007 Workshop on Web Mining and Social Network Analysis (p56-65). New York: ACM Press, 2007.

[2] H. Becker, M. Naaman, and L. Gravano, Beyond trending topics: Real-world event identification on Twitter. Paper presented at the 5th International Conference on Weblogs and Social Media, Barcelona, Spain, July 17-21, 2011.

[3] M. Naaman, J. Boase, and C.H. Lai, Is it really about me? Message content in social awareness streams. Paper presented at the Computer Supported Cooperative Work 2010, Georgia, USA, February 6-10, 2010. http://dx.doi.org/10.1145/1718918.1718953.

[4] C. Taylor, Social networking utopia isn't coming. CNN Tech. Retrieved on April 25, 2011, from http://articles.cnn.com/2011-06-27/tech/limits.social.networking.taylor _1_Twitter-users-facebook-friends-connections?_s=PM:TECH.

[5] The Huffington Post, Twitter user statistics show stunning growth. Retrieved on April 25, 2011, from http://www.huffingtonpost.com/2011/03/14/Twitter-user-statistics_n_8 35581.html.

[6] T. Lento, H.T. Welser, L. Gu, and M. Smith, The ties that blog: Examining the relationship between social ties and continued participation in the Wallop weblogging system. Paper presented at the workshop Weblogging Ecosystem: Aggregation, Analysis and Dynamics, Edinburgh, UK, May 23, 2006. Retrieved on April 25, 2011, from

http://www.blogpulse.com/www2006-workshop/papers/Lento-WelserGu-Smith-TiesThatBlog.pdf.

[7] S. Vieweg, A.L. Hughes, K. Starbird, and L. Palen, Microblogging during two natural hazards events: What Twitter may contribute to situational awareness. Paper presented at the SIGCHI Conference on Human Factors in Computing Systems, Atlanta, GA, USA, April 10-15, 2010. http://dx.doi.org/10.1145/1753326.1753486.

[8] A. Passant, T. Hastrup, U. Bojars, and J. Breslin, Microblogging: A semantic web and distributed approach. Retrieved on April 25, 2011, from http://CEUR-WS.org/Vol-368/paper11.pdf.

[9] T. Sakaki, M. Okazaki, and Y. Matsuo, Earthquake shakes Twitter users: Real-time event detection by social sensors. Paper presented at the 19th international conference on World Wide Web, Raleigh, NC, USA, 
April 26-30, 2010. http://dx.doi.org/10.1145/1772690.1772777.

[10] S. Milstein, A. Chowdhury, G. Hochmuth, B. Lorica, and R. Magoulas, Twitter and the micro-messaging revolution: Communication, connections, and immediacy-140 characters at a time. Sebastopol, CA: O'Reilly Media, 2008.

[11] O. Günther, H. Krasnova, D. Riehle, and V. Schönberg, Modeling microblogging adoption in the enterprise. Paper presented at the Fifteenth Americas Conference on Information Systems, San Francisco, August 6-9, 2009.

[12] M. Ebner, and M. Schiefner, Microblogging - more than fun? In I. Arnedillo Sánchez and P. Isaías (Eds.), Proceedings of the IADIS Mobile Learning Conference (p155-159). Lisbon, Portugal: IADIA, 2008.

[13] Fujitsu, Survey on the use of Twitter. Retrieved on April 25, 2011, from http://jp.fujitsu.com/group/fri/report/cyber/research/twitter/.

[14] M. Nakamura, and H. Deguchi, Cognitive-costed agent model of the microblogging network. Agent-Based Social Systems, 8, p75-84, 2011. http://dx.doi.org/10.1007/978-4-431-53907-0_6.

[15] M. Kin, Twitter social evolution theory in ten-thousand market. Tokyo: Asahi Publishing House, 2010.

[16] B.W. Gudykunst, Cross-cultural and intercultural communication. California: SAGE, 2003.

[17] G. Hofstede, Culture's consequences: International differences in work-related values. Sage Publications, Beverly Hills, CA, 1980.

[18] D. Oyserman, H.M. Coon, and M. Kemmelmeier, Rethinking individualism and collectivism: Evaluation of theoretical assumptions and meta-analyses. Psychological Bulletin, 128(1), p3-72, 2002. http://dx.doi.org/10.1037//0033-2909.128.1.3.

[19] T.E. Hall, and R.M. Hall, Understanding cultural differences. Maine: Intercultural Press, 1990.

[20] B.W. Gudykunst, and T. Nishida, Bridging Japanese/North American differences. California: SAGE, 1994.

[21] J. Miller, Beyond competence: Processes and strategies for effective intercultural Communication. Unpublished Monograph. Maxwell AFB, AL: Squadron Officer College, 2008.

[22] Dentsu Institute for Human Studies, Dataflow international media in Japan. Tokyo: Dataflow International, 1994.

[23] L. Fitton, M. Gruen, and L. Poston, Twitter for dummies ( $\left.2^{\text {nd }} e d.\right)$. New York: John Wiley \& Sons, 2010.

[24] R.B. Adler, and R.F. Proctor, Looking out, looking in (13th ed.). Boston: Cengage Learning, 2010.

[25] J.R. Davies, and O. Ikeno, The Japanese mind: Understanding contemporary Japanese culture. Boston: Tuttle Publishing, 2002. 